\title{
Virologic Response among Key Populations Living With HIV following a Switch to Dolutegravir-Based Regimen in South- ern Nigeria
}

\author{
Moses Katbi ${ }^{1 *}$, Adefisayo O Adedoyin ${ }^{1}$, Maryam Bello ${ }^{2}$, Adeoye Adegboye ${ }^{1}$, Oluwatosin Adeoye ${ }^{3}$, \\ Abiye Kalaiwo ${ }^{1}$, Kent Klindera ${ }^{4}$, Iyiola Faturiyele ${ }^{4}$, Tolu Alamu ${ }^{5}$, Homsuk Swomen 6 , Bartholomew \\ Ochonye $^{5}$, Michele RusselI ${ }^{1}$, Abdulmalik Abubakar ${ }^{7}$ and Babatunji Odelola ${ }^{1}$
}

${ }^{1}$ USAID, Abuja, Nigeria

${ }^{2}$ Hubert Department of Global Health, Emory Rollins School of Public Health, USA

${ }^{3}$ Society for Family Health, Justice Ifeyinwa Nzeako House, Abuja, Nigeria

${ }^{4}$ USAID, Ronald Reagan Building, USA

${ }^{5}$ Heartland Alliance, Abuja, Nigeria

${ }^{6}$ UNFPA, Nigeria

${ }^{7}$ Data Specialist with USAID, Nigeria

*Corresponding author: Moses Katbi, MD, MPH, MBA, FRSPH, Division Chief Prevention and Community Programs, USAID, Plot 1075 Diplomatic Drive, Central District Area, Abuja, Nigeria, Tel: +2348180321186

\begin{abstract}
Background: Achieving optimal virologic suppression among key population groups is essential to HIV epidemic control. The recommendation to transition HIV positive key populations from efavirenz-based regimen (Tenofovir, Lamivudine, Efavirenz (TLE)) to dolutegravir-based regimen (Tenofovir, Lamivudine, Dolutegravir (TLD)) considered the effectiveness of dolutegravir in achieving suppressed viral loads within a short period of time. The aim of this study was to investigate the virologic outcome of key populations (KP) transitioned to dolutegravir-based regimen.
\end{abstract}

Setting: Five key population (KP) treatment facilities in Southern Nigeria.

Methods: This is a retrospective descriptive study using secondary level program data. Eligible KP were clients already on TLE for at least 6 months, transitioned to TLD based on the new national HIV treatment guideline recommending TLD as the new first line treatment for HIV clients. We implemented a phased transition schedule switching clients from efavirenz to dolutegravir based regimen. We assigned clients to transitioned and delayed transition groups based on available secondary data from a retention and audit determination tool (RADET). Viral load test was conducted for all clients at 6 months after commencement of TLE.
Delayed transition group on TLE had repeat viral load test at 6 months while transitioned group on TLD at 3 months, the initial viral load test at 6 months was taken as baseline for both groups. Paired sample t-test was used to compare the means of the viral load test results pre and post TLD and McNemar test to compare the number of participants that achieved untransmitable viral load level of $<200$ copies/ml pre and post TLD. Binomial logistic regression was performed to ascertain the effects of age, target groups, sex and baseline viral load while on TLE on the likelihood that participants have a follow up viral load less than 200 copies/ $\mathrm{ml}$ while on TLD.

Results: Out of the 3,110 clients $(64.7 \%$ female, $35.3 \%$ male, mean age, $31.19 \pm 2.82$ ), 2,149 were transitioned from TLE to TLD regimen while 961 remained on TLE regimen awaiting transition within the period under review. At 3-months post TLD, $88 \%$ of transitioned participants had achieved untransmitable viral load suppression level (< 200 copies $/ \mathrm{ml}$ ) compared to $76.3 \%$ while on TLE (P value $<0.005$ ). Binomial logistic regression shows clients while on TLD had 3.064 times higher odds to achieve viral load less than 200 copies $/ \mathrm{ml}$ than when on TLE. The model was statistically significant, $X^{2}(5)=63.499, p<0.005$. It shows $56.0 \%$ (Nagelkerke $\mathrm{R}^{2}$ ) of the variance in follow up viral load while on TLD and correctly classified $88.1 \%$ of cases. 
Conclusion: Dolutegravir-based regimen showed superior virologic suppression in transitioned $\mathrm{KP}$ at 3-months compared to KP on TLE for 6-months.

\section{Keywords}

HIVIAIDS, Dolutegravir, Key populations, Efavirenz, Suppression, Viral load

\section{Introduction}

HIV/AIDS remains a major challenge to health and development in Nigeria. Despite great progress made towards achieving HIV epidemic control, Nigeria ranks second in global HIV burden based on the total number of people living with HIV (PLWH) Key population (KP) groups consisting of female sex workers (FSW), men who have sex with men (MSM), people who inject drugs (PWIDs), transgender people (TG) and people in closed settings (such as prisons) are disproportionately affected by the epidemic [1,2]. In sub-Saharan Africa, KPs account for about $25 \%$ of new HIV infections and in Nigeria, the prevalence among KP groups ranges from $9.3 \%$ to $37.6 \%$ [3], which is far higher than the total national prevalence of $1.4 \%$ [4]. The socio-cultural barriers and unfavorable political and legislative environment in Nigeria has further created a huge gap in the national response to HIV epidemic control among KPs [3]. As the HIV incidence stabilizes or declines among the general population, control efforts among KP groups is still challenging, thereby undermining programmatic success [5]. Hence, if greater attention is not paid to the strategic implementation of current and prospective HIV programs, KPs will continue to suffer a disproportionate burden of HIV/AIDS. Findings from the recent Nigeria HIV/AIDS Indicator and Impact Survey (NAIIS) indicated that the South-South zone had the highest prevalence of $3.1 \%$ in the country [6]. Likewise, the NAIIS survey also indicated that about $50 \%$ of people living with HIV (PLWH) in the country had achieved viral load suppression of HIV RNA of < 1000 copies per ml of plasma; a proportion much lower than the expected $90 \%$ target for the year 2020 [6,7]. Nonetheless, while research for a cure is still ongoing, the goal of treatment is to achieve sustained HIV viral load suppression allowing for immunological recovery and reduced transmission among the population. Achieving viral load suppression is dependent on adherence to highly active anti-retroviral therapy (HAART) and the use of optimized antiretroviral (ARV) drug regimens which significantly improves treatment outcomes in PLWH [8].

In order to achieve $95 \%$ virologic suppression among PLWH on treatment, the World Health Organization (WHO) in 2017 recommended that low and middle-income countries (LMIC) include in their HIV treatment regimens, highly potent $A R V s$ with lower toxicity and resistance and proven efficacy within diverse populations [8]. Subsequently, Dolutegravir-based regimens were recommended for adoption as the preferred first line regimen with over a million PLWH estimated to be currently on this regimen in LMICs, including Nigeria [9]. However, due to the presumed teratogenicity of the dolutegravir-based regimen, there were initial limitations to its use among pregnant women and women of reproductive age [10]. As a result, LMICs in the process of adopting the dolutegravir-based regimen as the preferred first line ARVs advised pregnant women and those of reproductive age to take the Dolutegravir-based regimen with caution [11]. Subsequent research findings have however assessed the risks of the dolutegravir-based regimen and demonstrated its effectiveness and high tolerability among all populations including women of reproductive age group. It is now documented that there is no significant difference in teratogenicity between Efavirenz and dolutegravir based regimen [12]. The Nigerian national HIV treatment guidelines as now been updated to include dolutegravir based regimen (TLD) as the preferred firstline and second-line treatment options [11]. As part of an intensified effort to accelerate HIV epidemic control, the government of Nigeria (GoN) and the President's Emergency Plan for AIDS Relief (PEPFAR) implemented a phased transitioning of clients from efavirenz to dolutegravir based regimen. This study explores the transition of key populations from efavirenz-based regimen to dolutegravir-based regimen and the virologic outcome among them in Southern Nigeria.

\section{Methods}

\section{Study design}

This is a multi-center, descriptive, comparative, retrospective study using secondary data from client health records. Data of all the participants in the sample frame (KP clients accessing care in the One Stop Shop involved) were included in the study.

The purpose of transitioning from TLE to TLD was fully explained to the clients. Clients were informed of the PEPFAR rapid advice and the Nigeria national guideline which indicates TLD as the preferred first line treatment. The benefits of TLD were also explained to clients who were able to make an informed decision. Civil society organizations (CSO) for HIV/AIDS were involved and accepted the benefits of TLD and encouraged PLWH to switch to TLD as preferred treatment. Clients were closely monitored for any side effects following the transition to TLD through short term clinic appointments. Clients were also offered adherence counselling and the viral load test results were explained to them. A small proportion that was found not to have achieved significant viral load suppression is being followed up with enhanced adherence counselling and further monitoring. All clients on TLE were eventually transitioned to TLD.

\section{Study description and sites}

USAID supported KP care project in Nigeria implemented a scheduled phased transition of PLWH from 
efavirenz plus tenofovir and lamivudine (TLE) to tenofovir plus lamivudine and dolutegravir (TLD) based regimen in five USAID-supported KP treatment sites across five zones in Lagos, Akwa-lbom and Cross River states of Nigeria in accordance with PEPFAR guidance. The treatment sites are one stop shops (OSS) and non-governmental organization (NGO) sites where KPs receive safe and non-discriminatory prevention, care and treatment services including viral load services done via referral to viral load reference laboratories in the respective states. Secondary data was collected and collated from the 3 states using RADET. The combined total client load of the sites at the time of data collection is 18,018 out of which 3110 were eligible for both baseline and follow up viral load (sample frame).

Clients were transitioned in phases based on their scheduled ART refill period. Transitioned group were moved from TLE to TLD while the delayed transition group consist of client who were still on TLE awaiting transition to TLD as the time of data collection. Participants viral load results was recorded as baseline (which represents the last viral load done while on TLE before commencement of TLD). A follow up viral load test was conducted for the transitioned group at three-months after transiting to TLD based on the new national guideline which specified three-month viral load assessment for clients on TLD. A repeat viral load test was conducted for the delayed transition TLE group at 6 months based on the national guideline.

\section{Study population and study period}

There were 3,110 HIV positive FSW, MSM, and PWID on ART eligible and enrolled from five USAID treatment sites who were served from October 2018 September 2019. All enrolled participants eligible for viral load test during the study period were assessed.

\section{Inclusion and exclusion criteria}

Inclusion criteria include being on TLE with initial VL test conducted 6 months post TLE (baseline viral load test), repeat viral load conducted 6 months post TLE or 3 months post TLD (follow up viral load test), while exclusion criteria include newly positive clients commenced directly on TLD, and having only one viral load test conducted with no follow-up/repeat test.

\section{Instruments \& Data collection methods and anal- ysis}

Secondary data was collected across five program zones in Akwa Ibom, Cross River and Lagos states. We conducted a data audit of the nationally approved clinical encounter documentation card (ART card) for PLWH. The audited data was collated and transmitted to an MS-Excel based template called RADET. RADET is a patient level data collection tool with information to track patient retention and quality of care - including HIV drug regimen(s) and viral load result(s) with appro- priate dates captured. Only patients who were active on ART (on TLD and TLE) during the period under review were included in the study. Thorough data cleaning was conducted for completeness and reliability. Clients must have been on TLE for at least 6 months and have had their viral load test conducted before they were transitioned to TLD. We carried out a repeat viral load test 3 months after commencement of TLD. The delayed transition group continued TLE for 6 months before follow-up viral load was done using the Roche (C6800 \& C8800) and Abbott PCR analyzers. We compared the pre TLD viral load results with the post TLD viral load results of both groups.

The data was analyzed using Statistical Package for Social Sciences (SPSS) version 24. The characteristics and distribution of participants' in the transitioned and delayed transition groups were summarized based on KP category, sex, age and geographical location.

The baseline and follow up viral load results were transformed into the $\log 10$ of the values.

Paired sample t-test was used to compare the means of the $\log 10$ of the baseline and follow up viral load test results of transitioned and delayed transition groups. One-way ANOVA was conducted to determine if there were differences in the means between the key population categories of each group. We used McNemar test to compare the number of respondents with untransmitable viral load level of $<200$ copies $/ \mathrm{ml}$ before and after start of TLD in the transitioned group. Binomial logistic regression was also done with age, sex target groups and baseline viral load used as adjustment variables.

\section{Data management and confidentiality}

The cleaned data was retrieved from the RADET and stored in a secured computer. The data was deidentified to keep participants' identity safe. Access to the data was restricted to authorized personnel only.

\section{Ethical consideration}

This project implemented by Heartland Alliance and funded by USAID Nigeria was approved for implementation by USAID and the Government of Nigeria and local research accreditation body. Ethical approval was gotten for the PEPFAR program through the Institutional Review Board (IRB) of the Federal Ministry of Health (FMOH). Transition from TLE to TLD was approved by the $\mathrm{FMOH}$ as well as the National Agency for the Control of AIDS (NACA). All data was deidentified to keep participants' identity safe. Access to the data was restricted to authorized personnel only. All clients consented to the use of their data for use but with utmost confidentiality of their identity.

\section{Results}

\section{Participant characteristics and distribution}

Table 1 shows the sociodemographic characteristics 
Table 1: Participant Characteristics and Distribution.

\begin{tabular}{|c|c|c|c|c|}
\hline Variable & $\begin{array}{l}\text { Delayed transition } \\
\text { (continued TLE) }\end{array}$ & $\begin{array}{l}\text { Transitioned to } \\
\text { TLD }\end{array}$ & $\begin{array}{l}\text { TOTAL } \mathrm{n}=3110 \\
\mathrm{n}(\%)\end{array}$ & $\begin{array}{l}\text { p-value (Chi } \\
\text { square) }\end{array}$ \\
\hline \multicolumn{5}{|l|}{ All clients } \\
\hline $\begin{array}{l}\text { KP Group } \\
\text { FSW } \\
\text { MSM } \\
\text { PWID }\end{array}$ & $\begin{array}{l}\text { N (row \%) } \\
573(31.1 \%) \\
236(29.9 \%) \\
152(31.9 \%)\end{array}$ & $\begin{array}{l}\text { N (row \%) } \\
1271(68.9 \%) \\
554(70.1 \%) \\
324(68.1 \%)\end{array}$ & $\begin{array}{l}\text { N (row \%) } \\
1844(100 \%) \\
790(100 \%) \\
476(100 \%)\end{array}$ & $p=0.721$ \\
\hline $\begin{array}{l}\text { Sex } \\
\text { Male } \\
\text { Female }\end{array}$ & $\begin{array}{l}\text { N (row \%) } \\
307(30.1 \%) \\
654(31.3 \%)\end{array}$ & $\begin{array}{l}\text { N (row \%) } \\
712(69.9 \%) \\
1437(68.7 \%)\end{array}$ & $\begin{array}{l}\text { N (row \%) } \\
1019(100 \%) \\
2091(100 \%)\end{array}$ & $p=0.515$ \\
\hline $\begin{array}{l}\text { Age } \\
<20 \\
20-24 \\
25-49 \\
>50\end{array}$ & $\begin{array}{l}\text { N (row \%) } \\
61(43.3 \%) \\
148(27.4 \%) \\
730(31.1 \%) \\
22(27.5 \%)\end{array}$ & $\begin{array}{l}\text { N (row \%) } \\
80(56.7 \%) \\
392(72.6 \%) \\
1619(68.9 \%) \\
58(72.5 \%)\end{array}$ & $\begin{array}{l}\text { N (row \%) } \\
141(100 \%) \\
540(100 \%) \\
2349(100 \%) \\
80(100 \%)\end{array}$ & $p=0.001$ \\
\hline $\begin{array}{l}\text { Geographic Zone } \\
\text { AKS_ZONE A } \\
\text { AKS_ZONE B } \\
\text { CRS_ZONE A } \\
\text { CRS_ZONE B } \\
\text { LAGOS_ZONE A }\end{array}$ & $\begin{array}{l}\mathbf{N}(\text { row \%) } \\
221(26.8) \\
30(21 \%) \\
690(34.7 \%) \\
15(11.6 \%) \\
5(19.2 \%)\end{array}$ & $\begin{array}{l}\mathbf{N}(\text { row \%) } \\
604(73.2 \%) \\
113(79 \%) \\
1297(65.3 \%) \\
114(88.4 \%) \\
21(80.8 \%)\end{array}$ & $\begin{array}{l}\mathbf{N}(\text { row } \%) \\
825(100 \%) \\
143(100 \%) \\
1987(100 \%) \\
129(100 \%) \\
26(100 \%)\end{array}$ & $p<0.0005$ \\
\hline \multicolumn{5}{|l|}{ FSW Only } \\
\hline $\begin{array}{l}\text { Sex } \\
\text { Male } \\
\text { Female }\end{array}$ & $\begin{array}{l}\mathbf{N}(\text { row \%) } \\
0(0 \%) \\
573(31.1 \%)\end{array}$ & $\begin{array}{l}\mathbf{N}(\text { row \%) } \\
0(0 \%) \\
1271(68.1 \%)\end{array}$ & $\begin{array}{l}\mathbf{N}(\text { row } \%) \\
0(0 \%) \\
1844(100 \%)\end{array}$ & \\
\hline $\begin{array}{l}\text { Age } \\
<20 \\
20-24 \\
25-49 \\
>50\end{array}$ & $\begin{array}{l}\text { N (row \%) } \\
44(49.9 \%) \\
93(28.1 \%) \\
425(30.8 \%) \\
11(25 \%)\end{array}$ & $\begin{array}{l}\text { N (row \%) } \\
45(50.1 \%) \\
238(71.9 \%) \\
955(69.2 \%) \\
33(75 \%)\end{array}$ & $\begin{array}{l}\mathbf{N}(\text { row } \%) \\
89(100 \%) \\
331(100 \%) \\
1380(100 \%) \\
44(100 \%)\end{array}$ & \\
\hline $\begin{array}{l}\text { Geographical Zone } \\
\text { AKS_ZONE A } \\
\text { AKS_ZONE B } \\
\text { CRS_ZONE A } \\
\text { CRS_ZONE B } \\
\text { LAGOS_ZONE A }\end{array}$ & $\begin{array}{l}\mathbf{N}(\text { row \%) } \\
149(29 \%) \\
17(20 \%) \\
399(34.8 \%) \\
7(7.7 \%) \\
1(14.3 \%)\end{array}$ & $\begin{array}{l}\mathbf{N}(\text { row \%) } \\
364(71 \%) \\
68(80 \%) \\
749(65.2 \%) \\
84(92.3 \%) \\
6(85.7 \%)\end{array}$ & $\begin{array}{l}\mathbf{N}(\text { row } \%) \\
513(100 \%) \\
85(100 \%) \\
1148(100 \%) \\
91(100 \%) \\
7(100 \%)\end{array}$ & \\
\hline \multicolumn{5}{|l|}{ MSM only } \\
\hline $\begin{array}{l}\text { Sex } \\
\text { Male } \\
\text { Female }\end{array}$ & $\begin{array}{l}\mathbf{N}(\text { row \%) } \\
236(29.9 \%) \\
0(0 \%)\end{array}$ & $\begin{array}{l}\mathbf{N}(\text { row \%) } \\
554(70.1 \%) \\
0(0 \%)\end{array}$ & $\begin{array}{l}\mathbf{N}(\text { row \%) } \\
790(100 \%) \\
0(0 \%)\end{array}$ & \\
\hline $\begin{array}{l}\text { Age } \\
<20 \\
20-24 \\
25-49 \\
>50\end{array}$ & $\begin{array}{l}\text { N (row \%) } \\
8(25 \%) \\
43(26.5 \%) \\
176(30.8 \%) \\
9(36 \%)\end{array}$ & $\begin{array}{l}\mathbf{N}(\text { row \%) } \\
24(75 \%) \\
119(73.5 \%) \\
395(69.2 \%) \\
16(64 \%)\end{array}$ & $\begin{array}{l}\mathbf{N}(\text { row } \%) \\
32(100 \%) \\
162(100 \%) \\
571(100 \%) \\
25(100 \%)\end{array}$ & \\
\hline $\begin{array}{l}\text { Geographical Zone } \\
\text { AKS_ZONE A } \\
\text { AKS_ZONE B } \\
\text { CRS_ZONE A } \\
\text { CRS_ZONE B } \\
\text { LAGOS_ZONE A }\end{array}$ & $\begin{array}{l}\text { N (row \%) } \\
41(22.7 \%) \\
5(17.2 \%) \\
183(33.7 \%) \\
3(15.8 \%) \\
4(22.2 \%)\end{array}$ & $\begin{array}{l}\mathbf{N}(\text { row } \%) \\
140(77.3 \%) \\
24(82.8 \%) \\
360(66.3 \%) \\
16(84.2 \%) \\
14(77.8 \%)\end{array}$ & $\begin{array}{l}\mathbf{N}(\text { row } \%) \\
181(100 \%) \\
29(100 \%) \\
543(100 \%) \\
19(100 \%) \\
18(100 \%)\end{array}$ & \\
\hline
\end{tabular}




\begin{tabular}{|l|l|l|l}
\hline Sex & $\mathrm{N}($ row $\%)$ & $\mathrm{N}($ row $\%)$ & $\mathrm{N}($ row \%) \\
Male & $71(31 \%)$ & $158(6 \%)$ & $229(100 \%)$ \\
Female & $81(32.8 \%)$ & $166(67.2 \%)$ & $247(100 \%)$ \\
\hline Age & $\mathrm{N}($ row $\%)$ & $\mathrm{N}($ row $\%)$ & $\mathrm{N}($ row $\%)$ \\
$<\mathbf{2 0}$ & $9(45 \%)$ & $11(55 \%)$ & $20(100 \%)$ \\
$\mathbf{2 0 - 2 4}$ & $12(25.5 \%)$ & $35(74.5 \%)$ & $47(100 \%)$ \\
$\mathbf{2 5 - 4 9}$ & $129(32.4 \%)$ & $269(67.6 \%)$ & $398(100 \%)$ \\
$\mathbf{>} \mathbf{5 0}$ & $2(18.2 \%)$ & $9(81.8 \%)$ & $11(100 \%)$ \\
\hline Geographical Zone & $\mathrm{N}($ row $\%)$ & $\mathrm{N}($ row $\%)$ & $\mathrm{N}($ row $\%)$ \\
AKS_ZONE A & $31(23.7 \%)$ & $100(76.3 \%)$ & $131(100 \%)$ \\
AKS_ZONE B & $8(27.6 \%)$ & $21(72.4 \%)$ & $29(100 \%)$ \\
CRS_ZONE A & $108(36.5 \%)$ & $188(63.5 \%)$ & $296(100 \%)$ \\
CRS_ZONE B & $5(26.3 \%)$ & $14(73.7 \%)$ & $19(100 \%)$ \\
LAGOS_ZONE A & $0(0 \%)$ & $1(100 \%)$ & $1(100 \%)$ \\
\hline
\end{tabular}

Table 2: Mean difference in log of viral load of the transitioned group and delayed transition group.

\begin{tabular}{|c|c|c|c|c|c|c|c|c|}
\hline \multirow[t]{2}{*}{ KP category } & \multicolumn{4}{|c|}{ Transitioned 3 months on TLD } & \multicolumn{4}{|c|}{ Delayed transition 6 months on TLE } \\
\hline & $\begin{array}{l}\text { Mean Log10 } \\
\text { of } 1^{\text {st }} \mathrm{VL}\end{array}$ & $\begin{array}{l}\text { Mean Log10 } \\
\text { of } 2^{\text {nd }} V L\end{array}$ & $\begin{array}{l}\text { Mean Log10 } \\
\text { reduction }\end{array}$ & $p$ - value & $\begin{array}{l}\text { Mean Log10 } \\
\text { of } 1^{\text {st }} V L\end{array}$ & $\begin{array}{l}\log 10 \text { of } \\
2^{\text {nd }} V L\end{array}$ & $\begin{array}{l}\text { Mean Log } 10 \\
\text { reduction }\end{array}$ & p-value \\
\hline FSW & 2.110 & 1.498 & 0.612 & $<0.005$ & 2.195 & 1.596 & 0.599 & $<0.005$ \\
\hline MSM & 2.106 & 1.435 & 0.617 & $<0.005$ & 2.175 & 1.788 & 0.387 & $<0.005$ \\
\hline PWID & 1.970 & 1.400 & 0.570 & $<0.005$ & 2.051 & 1.728 & 0.323 & $<0.005$ \\
\hline All categories & 2.088 & 1.467 & 0.621 & $<0.005$ & 2.112 & 1.528 & 0.584 & $<0.005$ \\
\hline
\end{tabular}

Table 3: ANOVA for transitioned and delayed transition groups.

\begin{tabular}{|c|c|c|c|c|c|c|c|}
\hline & & \multicolumn{3}{|c|}{ Transitioned group (study) } & \multicolumn{3}{|c|}{ Delayed transition group (study) } \\
\hline & & df & $\mathrm{F}$ & Sig. & df & $\mathrm{F}$ & Sig. \\
\hline \multirow{3}{*}{$\begin{array}{l}\text { Last viral load } \\
\text { on regimen at } \\
\text { start }\end{array}$} & Between KP categories & 2 & 2.115 & 0.121 & 2 & 0.402 & 0.669 \\
\hline & Within KP categories & 2146 & & & 958 & & \\
\hline & Total & 2148 & & & 960 & & \\
\hline \multirow{3}{*}{$\begin{array}{l}\text { Current viral } \\
\text { load on TLD } \\
\text { regimen }\end{array}$} & Between KP categories & 2 & 0.198 & 0.821 & 2 & 1.902 & 0.150 \\
\hline & Within KP categories & 2146 & & & 958 & & \\
\hline & Total & 2148 & & & 960 & & \\
\hline
\end{tabular}

of 3,110 participants. Across the data analyzed, $67.2 \%$ (n $=2091)$ were females and $32.8 \%(n=1019)$ were males. Majority of the respondents $(75.5 \% ; n=2349)$ fell within the $25-49$ age range, while $4.5 \%(n=141)$ were less than 20 years of age. Participants were classified into transitioned and delayed transition groups based on TLD status during data analysis. Chi square shows the distribution by age group and geographic region differs by transition group vs. delayed transition group.

\section{Mean Difference in Log10 of baseline and follow up viral load}

Mean difference in log10 of viral load of the transitioned group ( 3 months on TLD after transition) and delayed transition group (continued TLE for 6 months before $2^{\text {nd }} V L$ ). Paired t-test conducted shows the, mean difference in the log10 for the transitioned group was statistically significant at 3 months for all categories while in delayed transition group, the difference was statistically significant at 6 months (Table 2).

\section{ANOVA for transitioned and delayed transition groups}

There were no statistically significant differences between transitioned key population categories' viral load means as determined by one-way ANOVA $(F(2)=2.115$, $p=0.121)$. Similarly, there were no statistically significant differences between the delayed transition key population categories' viral load means as determined by one-way ANOVA $(F(2)=0.402, p=0.669)$ (Table 3$)$.

Transitioned group (Table 4) shows 395 clients who did not achieve viral load of less than 200 copies $/ \mathrm{ml}$ while on TLE achieved it within 3 months of being on TLD. While 142 clients who initially had viral load of 200 copies/ml while on TLE went above this mark while on TLD. This is statistically significant using McNemar test $(p<0.005)$. Delayed transition group (Table 4$)$ shows 113 clients who did not achieve viral load of less than 200 copies/ml while on TLE achieved it within 3 months of being on TLD. While 45 clients who initially had vi- 
Table 4: McNemar test for Transitioned and delayed transition groups.

\begin{tabular}{|c|c|c|c|c|c|}
\hline \multicolumn{6}{|c|}{ Transitioned group (Study) } \\
\hline & & \multicolumn{2}{|c|}{$\begin{array}{l}\text { Achieved Viral load of less than } 200 \mathrm{cp} / \\
\text { ml } 3 \text { months after TLD transition }\end{array}$} & \multirow[b]{2}{*}{ Total } & p-value \\
\hline & & Yes & No & & \multirow[t]{4}{*}{$p<0.005$} \\
\hline \multirow{3}{*}{$\begin{array}{l}\text { Achieved Viral load of less } \\
\text { than } 200 \mathrm{cp} / \mathrm{ml} \text { on TLE }\end{array}$} & Yes & 1498 & 142 & 1640 & \\
\hline & No & 395 & 114 & 509 & \\
\hline & Total & 1893 & 256 & 2149 & \\
\hline \multicolumn{6}{|c|}{ Delayed transitioned group (Control) } \\
\hline & & \multicolumn{3}{|c|}{$\begin{array}{l}\text { Achieved Viral load of less than } 200 \mathrm{cp} / \mathrm{ml} 6 \text { months } \\
\text { after continuing on TLE (not transitioned). }\end{array}$} & $p$-value \\
\hline & & Yes & No & Total & \multirow[t]{4}{*}{$p<0.005$} \\
\hline \multirow{3}{*}{$\begin{array}{l}\text { Achieved Viral load of less } \\
\text { than } 200 \mathrm{cp} / \mathrm{ml} \text { on TLE }\end{array}$} & Yes & 732 & 45 & 777 & \\
\hline & No & 113 & 71 & 184 & \\
\hline & Total & 845 & 116 & 961 & \\
\hline
\end{tabular}

Table 5: Binomial Logistic regression for the transitioned group.

\begin{tabular}{|c|c|c|c|c|c|c|c|c|}
\hline & \multirow[t]{2}{*}{$\mathrm{B}$} & \multirow[t]{2}{*}{ S.E. } & \multirow[t]{2}{*}{ Wald } & \multirow[t]{2}{*}{$d f$} & \multirow[t]{2}{*}{ p-value. } & \multirow[t]{2}{*}{ Odds ratio } & \multicolumn{2}{|c|}{ 95\% C.I. for odds ratio } \\
\hline & & & & & & & Lower & Upper \\
\hline $\operatorname{Sex}(1)$ & -0.237 & 0.353 & 0.451 & 1 & 0.502 & 0.789 & 0.395 & 1.575 \\
\hline Target group & & & 0.986 & 2 & 0.611 & & & \\
\hline Target group(1) & 0.109 & 0.268 & 0.166 & 1 & 0.684 & 1.115 & 0.660 & 1.885 \\
\hline Target group(2) & -0.255 & 0.282 & 0.821 & 1 & 0.365 & 0.775 & 0.446 & 1.346 \\
\hline Age recoded & 0.074 & 0.126 & 0.342 & 1 & 0.559 & 1.076 & 0.841 & 1.377 \\
\hline $\begin{array}{l}\text { Baseline viral load (last VL on } \\
\text { TLE before transition to TLD) }\end{array}$ & 1.120 & 0.138 & 65.420 & 1 & 0.000 & 3.064 & 2.336 & 4.020 \\
\hline Constant & -3.525 & 0.488 & 52.213 & 1 & 0.000 & 0.029 & & \\
\hline
\end{tabular}

ral load of 200 copies/ml while on TLE went above this mark while on TLD. This is also statistically significant using McNemar test $(p<0.005)$.

A binomial logistic regression (Table 5) was performed to ascertain the effects of age, target groups (FSW, PWID, MSM)), sex and baseline viral load while on TLE on the likelihood that participants have a follow up viral load less than 200 copies/ml while on TLD. The logistic regression model was statistically significant, $\chi^{2}(5)=63.499, p<0.005$. The model explained $56.0 \%$ (Nagelkerke $\mathrm{R}^{2}$ ) of the variance in follow up viral load while on TLD and correctly classified $88.1 \%$ of cases. Of the four predictor variables only one was statistically significant: baseline viral load while on TLE (last viral load recode $<200 \mathrm{cp} / \mathrm{ml}$ ) (as shown in Table 4). Clients while on TLD had 3.064 times higher odds to achieve viral load less than 200 copies/ml than when on TLE.

\section{Discussion}

This study focused on Key population groups (FSW, PWID and MSM) in the South of Nigeria with the highest HIV prevalence rates. To the best of our knowledge, this is the first study among key population that looks at transitioning of KPs from TLE to TLD and it effect on HIV virologic suppression. Therefore, the study contributes new information to the body of knowledge on dolutegravir based regimen among KPs. The study has been able to show that dolutegravir based regimen is superior to efavirenz based regimen among KP groups. KPs have peculiar characteristics and are therefore at increased risk for HIV compared to the general population. In addition to practicing high risk behavior with their peers, some KP groups are also known to have close sexual relationship with members of the general population and are disproportionately affected by HIV. They are known to contribute about 35 percent to new infection rates in Nigeria [13]. Focusing high impact strategies (such as transitioning from TLE to TLD) on high risk groups such as KPs is required to control the HIV epidemic.

Our study shows that most of the clients were female PLWH on ART, which is consistent with UNAIDS data signifying that HIV infection is disproportionately higher among females in Nigeria [14]. We found that about 7 out of 10 participants on TLE were able to achieve un- 
transmitable viral load value of less than $200 \mathrm{c} / \mathrm{ml}$, while 9 out of 10 clients were able to achieve the same viral load level after transitioning to TLD. This indicates that TLD is more effective in achieving untransmitable viral suppression level among KP groups. Clients switched to TLD based regimen showed superior virologic suppression despite only being on TLD combination for three months compared to being on TLE for a longer period of six months. A finding that is important considering the high-risk level of KP groups in driving the HIV epidemic.

The results showed that more participants achieved virologic suppression at 3 months when participants were transitioned to TLD compared to TLE, more participants on TLD also achieved untransmitable viral load level of $<200 \mathrm{c} / \mathrm{ml}$ in three months compared to untransmitable viral load level achieved while on TLE for a longer period of six months. Studies have shown that it takes a minimum of 6 months to observe a reliable and significant viral load drop in patients on TLE. Additionally, no significant difference was demonstrated in the mean of the viral loads when PWID, MSM and PWID were compared.

Our findings are consistent with previous studies that have assessed and demonstrated the efficacy of dolutegravir-based regimen in the treatment of PLWH [15-17]. A large retrospective cohort study in Brazil using program level data also shows viral suppression by 12 months was 84.0 percent with TLE and $90.5 \%$ with TLD. This study concluded that dolutegravir based regimen is superior to efavirenz based regimen in suppressing viral load. Another retrospective cohort study also carried out in Brazil analyzes cumulative viremia under the most frequently used ART regimens, TLD and TLE over a 12 months period concluded that cumulative viremia was lower in clients on TLD compared to those on TLE. These studies support the WHO's recommendation of dolutegravir-based regimen as the preferred first line ART regimen in the management of HIV in achieving viral load suppression faster than any other regimen [11].

Furthermore, another significance of our findings is that it shows that rapid virologic suppression towards untransmitable levels that is important for HIV prevention can be achieved among KP who are disproportionate affected by HIV [18]. Although PLWH with undetectable viral loads still have the HIV virus, studies have shown that they are unable to transmit it to others in the population. Attaining untransmitable viral load level is important among KPs because they account for $35 \%$ of new infection rate even though KPs constitute only $3.4 \%$ of the Nigerian population [13]. The need to ensure that these key populations achieve virologic suppression and remain untransmissible in the population cannot be overstressed.

There are a few limitations of our study which gives room for future research that will improve the body of knowledge in this area. Our study did not consider metrics to access if TLD combination achieved untransmitable virologic suppression faster than TLD. We did not also explore reasons why a few KP-PLWH had increased viral load after transitioning to TLD, this could however be due to factors related to adherence which is unproven. Since this is a retrospective analysis using secondary data, future experimental studies that would look at control versus study groups is strongly encouraged. Our study using rigorous inferential statistics and binomial regression however demonstrated that TLD offers superior efficacy compared to TLE which needs to be explored further.

\section{Conclusion}

The WHO has reiterated the importance of the use of optimized antiretroviral (ARV) drug regimens, which can significantly improve HIV treatment outcomes with impact on adherence to treatment, suppression of viral load and general improvement in the quality of life of people living with HIV [8]. From our study, TLD has shown superior efficacy than TLE in reducing the viral load level of Key population living with HIV. There should be significant drive to ramp up uptake of TLD among key population living with HIV (KP-PLWH) in order to get better treatment outcome among these groups who are disproportionately affected by HIV/AIDS in Nigeria [1921].

\section{References}

1. Federal Ministry of Health Nigeria (2013) National HIV \& AIDS and reproductive health survey (NARHS Plus II, 2012).

2. Awoyemi Abayomi Awofala, Olusegun Emmanuel Ogundele (2018) HIV epidemiology in Nigeria. Saudi J Biol Sci 25: 697-703.

3. Asuquo G, Owolabi D, Onoja A, Okoro U, Durueke F (2014) Community needs assessment of key populations-at-risk of HIVIAIDS in Nigeria's capital territory. BMC Infect Dis 14: 29.

4. UNAID (2019) Ending the AIDS epidemic. Abuja.

5. Wheeler T, Emmanuel G, Trout C (2017) A differentiated care model for prevention, treatment and care of HIV for key populations in a violent and criminalized context Heartland alliance in Nigeria.

6. NAIIS (2019) Nigeria HIVIAIDS indicator and impact survey - National summary sheet of preliminary findings. Abuja.

7. UNAIDS (2014) 90-90-90 an ambitious treatment target to help end the AIDS epidemic.

8. World Health Organization (WHO) (2017) Transition to new antiretroviral drugs in HIV programmes: Clinical and programmatic consideration.

9. World Health Organization (WHO) (2019) Update of recommendations on first- and second-line antiretroviral regimens. Geneva.

10. National AIDS and STIs control program (2018) Rapid advice: Recommendations for first line antiretroviral therapy in Nigeria. 
11. World Health Organization (WHO) (2019) WHO recommends dolutegravir as preferred HIV treatment option in all populations.

12. Kintu K, Malaba TR, Nakibuka J, Papamichael C, Colbers A, et al. (2020) Dolutegravir versus efavirenz in women starting HIV therapy in late pregnancy (DolPHIN-2): An open-label, randomized controlled trial. The Lancet HIV 7: e332-e339.

13. AVERT (2018) HIV and AIDS in Nigeria.

14. UNAIDS (2018) Nigeria.

15. Meireles MV, Pascom ARP, Duarte EC, McFarland W (2019) Comparative effectiveness of first-line antiretroviral therapy: Results from a large real-world cohort after the implementation of dolutegravir. AIDS 33: 1663-1668.

16. Phillips AN, Venter F, Havlir D, Pozniak A, Kuritzkes D, et al. (2019) Risks and benefits of dolutegravir-based antiret- roviral drug regimens in sub-Saharan Africa: a modelling study. The Lancet HIV 6: e116-e127.

17. Pascom AR, Pinho RE, Rick F, Veras NMC, Perini FDB, et al. (2019) Comparison of cumulative viraemia following treatment initiation with different antiretroviral regimens: a real-life study in Brazil. J Int AIDS Soc 22: e25397.

18. $U=U$ taking off in 2017 (2017) The Lancet HIV Editorial 4: e475.

19. Baral S, Trapence G, Motimedi F, Umar E, lipinge S, et al. (2009) HIV Prevalence, Risks for HIV Infection, and Human Rights among Men Who Have Sex with Men (MSM) in Malawi, Namibia and Botswana. PLoS One 4: e4997.

20. OGBC Health (2007) Overview of the feminization of HIV/ AIDS in sub-Saharan Africa.

21. WHO (2018) Viral suppression for HIV treatment success and prevention of sexual transmission of HIV. 